\title{
Uma análise contextual da filosofia: entre Desvios e Conceitos
}

\author{
Simone Carlos da Silva
}

\section{RESUMO}

Diante da perspectiva de reinserção da Filosofia como disciplina obrigatória no currículo do ensino médio, discutimos o molde educacional erigido pelo contexto da sociedade capitalista a partir do modelo sugerido por Deleuze, Gatarri e Walter Benjamin, utilizando deste último o método do desvio, que se furta ao caráter esquematizador e sistêmico próprio do técnico, e dos primeiros, a resposta ao "o que é a filosofia?" na forma de criação de conceitos.

Palavras-chave: Filosofia. Reinserção. Representação. Conceitos.

\section{ABSTRACT}

\section{A contextual analysis of philosophy : between Deviations and Concepts}

Faced with the prospect of reintegration of Philosophy as a compulsory subject in the high school curriculum, discuss the educational mold erected by the context of capitalist society from the model suggested by Deleuze, Gatarri and Walter Benjamin, using the latter method of diversion, which steals the scheduler itself and systemic character of the coach, and of the first, the answer to "What is philosophy?" in the form of creating concepts. Keywords: Philosophy. Reintegration. Representation. Concepts.

\section{INTRODUÇÃO}

A educação é um bem necessário posto que é uma dimensão da vida social, um direito humano inegociável. Em tese tal afirmação se sustenta, todavia, na prática social seu desdobramento se configura condicionalmente na 
barganha desse direito. Pois o modelo educacional erigido a partir do capitalismo subtrai conhecimentos clássicos da filosofia, das artes e das ciências que servem à formação digna dos sujeitos, capazes de se compreender dentro de uma teia social, política, cultural etecetera. Em contrapartida a esta formação, no contexto capitalista o que se prioriza são os interesses mercantis que substituem saberes teoréticos ${ }^{1}$ por saberes pragmáticos que sirvam as necessidades do mecanismo lógico do capital, que por sua vez, instaura um modelo educacional unilateral voltado para uma formação tecnicista.

Fabrica-se uma educação ideologizada e adaptativa, criadora de ilusões com o modus operandi empresarial, na qual o empreendedorismo se espraia de maneira vulgar e deslocada da realidade, como ilustra o ensino técnico hoje propagado pelos organismos internacionais como a Organização das Nações UnidasONU e o Banco Internacional para Reconstrução e Desenvolvimento - BIRD (Banco Mundial-BM)[...]Neste sentido, a educação escolar, denominada de cidadã, pelos referidos órgãos e pelos governos, contribui sobremaneira para formar uma subjetividade passiva conformada à realidade, especialmente por meio da suposta inclusão do chamado cidadão planetário nas malhas das relações sociais, sob a insígnia de indivíduos praticistas de segunda ou terceira classes, servidores passíveis do mercado (SOARES, 2012, p. 43).

Não à toa, a sociabilidade moderna capitalista preserva a imagem do sujeito atrelado a uma visão burguesa de indivíduo isolado, egoísta, competitivo que busca realizar seus próprios interesses particulares ${ }^{2}$. Essa

\footnotetext{
1 Segundo Aristóteles, o homem é um ser racional, pois por natureza tem o desejo de conhecer. O ser humano vive da arte e do raciocínio. Para além dos sentidos tem a capacidade da memória, o que o torna mais inteligente que outros animais que não podem recordar, pois vivem de imagens e recordações. Da memória humana incide a experiência e desta a arte e a ciência que brota genuinamente do conhecimento teorético, ou seja, aquele que visa à satisfação. Por isto, os saberes teoréticos são mais importantes do que os saberes práticos porque visam à satisfação e não apenas à necessidade como acontece com os saberes práticos. A ciência que resulta do conhecimento teorético, especulativo é o saber das causas e da razão de ser (Cf. ARISTÓTELES. Os pensadores. In:metafísica. São Paulo, Abril, 1984)

${ }^{2}$ Para a grande maioria dos estudantes, a ciência é uma escola profissionalizante. Já que "ciência não tem nada a ver com a vida", então ela deve moldar com exclusividade a vida de quem segue. Entre as reservas mais inocentes e mentirosas que se têm perante ela, encontrase a expectativa de que ela deva ajudar este ou aquele a se prepararem para uma profissão. A profissão decorre tão minimante da ciência que esta pode até destruí-la. Pois em consonância
} 
visão é propagada através da formação pedagógica pragmática que intenta formar um individuo submetido ao mercado e dissociado da comunidade e dos nexos que o constitui. Ora, seguindo essa lógica a educação forma homens úteis e concretos que captam informações utilitárias à experiência e ao mercado. Reduzidos a seres praticistas, estes indivíduos recebem um saber que atende as necessidades reprodutivas do capital. A participação dos Bancos em projetos escolares como, por exemplo, o Programa Ensino Médio Inovador/Jovem de Futuro (ProEMI/JF) ${ }^{3}$ desenvolvido pelo Unibanco é apenas uma forma de assegurar a formação aligeirada e especializada desses indivíduos, que agregam valores na medida em que se adequam as exigências do valor de troca ${ }^{4}$, uma vez que sua formação é voltada para o mercado de trabalho e não para proporcionar a liberdade e autonomia. Vivemos um momento em que os bancos mantêm um verdadeiro domínio sobre a educação ${ }^{5}$ em que as instituições financeiras forjam o papel educacional.

Neste cenário em que o que está em voga é o imediatismo do conhecimento, o ensino da filosofia cai em descrédito no que se refere ao campo profissional. Pois não raro é atribuído à filosofia o aspecto de inutilidade, uma vez que seu conhecimento não serve à imediaticidade prática, mas, grosso modo, ao conhecimento crítico das realidades e busca de compreensão

com a sua essência, ela não tolera nenhuma solução por si mesma; a ciência obriga o pesquisador a ser de certo modo sempre professor, jamais Ihe impõe as formas das profissões públicas de médico, jurista, docente universitário (BENJAMIN,2009,p. 32).

3 O Programa Ensino Médio Inovador/Jovem de Futuro (ProEMl/JF) reflete uma parceria público privada entre o Ministério da Educação (MEC), cinco Secretarias Estaduais de Educação e o Instituto Unibanco [...] Como política pública nacional, o ProEMI propõe o redesenho curricular do Ensino Médio, focado em um currículo dinâmico, flexível e compatível com as exigências da sociedade contemporânea, contemplando uma ampliação do tempo dos estudantes na escola e uma diversidade de práticas pedagógicas que atendam às expectativas e às necessidades dos jovens. Disponível em http://www.portalinstitutounibanco.org.br/index.php?option=com content\&view=article\&id=10\&lt emid=8 acesso em 29/09/2014

${ }^{4}$ A utilidade de uma coisa faz dela um valor de uso [...] uso ou no consumo. Os valores de uso constituem o conteúdo material da riqueza, qualquer que seja a forma social desta. Na forma de sociedade a ser por nós examinada, eles constituem, ao mesmo tempo, os portadores materiais do - valor de troca. O valor de troca aparece, de início, como a relação quantitativa, a proporção na qual valores de uso de uma espécie se trocam contra valores de uso de outra espécie, uma relação que muda constantemente no tempo e no espaço. O valor de troca parece, portanto, algo casual e puramente relativo; um valor de troca imanente, intrínseco à mercadoria (Economistas)

${ }^{5}$ [...] inaugurada por volta dos anos 70 do século XX, quando o Banco Mundial passou a operar de modo mais incisivo no setor educacional, tornando-se uma espécie de ministério mundial da educação dos países periféricos ( Sousa, 2012, p.48) 
do sujeito dentro de uma totalidade sócio-histórica, em que o sujeito é levado a encontrar-se genérico e humanamente, desenvolver sua potencialidade criativa para uma autoconstrução, autocriação em relação com o outro e com o mundo.

Confrontada com essa nova conjuntura socioeducacional a Filosofia corre mais uma vez o risco de ser sucumbida pelo tecnicismo ou mesmo excluída novamente da grade curricular do ensino médio como aconteceu em 1971. Essa é a preocupação que nos toca, pois a filosofia no Brasil sempre teve dificuldade para conseguir uma estabilidade no currículo escolar. ${ }^{6}$

A Filosofia no decurso do seu histórico escolar no Brasil antes de aceita como disciplina obrigatória sofreu algumas represálias. Retirada em 1971 do currículo do ensino médio, quando foi realizada a reforma tecnicista, que priorizava a formação técnico-profissionalizante em detrimento das disciplinas de humanidades, a filosofia ficou reclusa ao caráter optativo. Em 1978 foi completamente excluída do ensino secundário e somente retorna mais tarde em 1980 sob a pressão dos departamentos de filosofia das universidades brasileiras $^{7}$. Retorna apenas como disciplina optativa, integrando um currículo na forma de temas transversais e só a partir de 2008 é aprovada por lei como disciplina obrigatória.

Diante de tais reveses estruturais em torno do estudo da filosofia no ensino secundário trazemos à baila as consequências que respingam hoje no ensino filosófico, tais como os desafios didáticos e pedagógicos de trabalhar

\footnotetext{
${ }^{6}$ RODRIGO, "O ensino de Filosofia na escola secundária existe no Brasil desde o período colonial, embora sempre com grande dificuldade para conquistar um lugar estável no currículo escolar. Seu sentido e suas funções também oscilaram muito ao longo desses quinhentos anos de história ao sabor das diferentes orientações que foram sendo conferidas a esse nível de ensino", 2009, p. 7

${ }^{7}[. .$.$] após a retirada da disciplina dos currículos com a reforma tecnicista de 1971, os$ departamentos de filosofia das universidades brasileiras empreenderam um movimento de crítica de sua retirada e defesa de seu retorno. Esse movimento teve êxito parcial quando, em meados dos anos de 1980, foi aprovada a inclusão da disciplina filosofia como opcional, na parte diversificada do currículo. Os ecos desse movimento fizeram-se presentes nos debates para a construção da Lei de Diretrizes e Bases da Educação Nacional (LDB), após a promulgação da Constituição de 1988, e o projeto aprovado na Câmara previa filosofia e sociologia como disciplinas obrigatórias. O Substitutivo Darci Ribeiro, porém, que seria aprovado como lei n. 9.394/96, em seu espírito flexibilizador e "minimalista", optou por afirmar conhecimentos de filosofia e sociologia como obrigatórios, mas sem definir seu caráter disciplinar. O Ministério da Educação, durante a gestão de Paulo Renato de Sousa , claramente optou por seu ensino na forma de temas transversais [...] (RODRIGO, Lídia Maria. Filosofia em sala de aula. IN: S. Galo. Prefácio. Campinas, SP: Autores Associados,2009.)
} 
com um público especializado que se relaciona com o saber escolar reduzido ao utilitarismo. Os desafios didáticos que surgem questionam o ensino de filosofia para um público especializado e a motivação possível para despertar o interesse dos alunos de nível médio para o estudo da filosofia. Quanto à epistemologia indaga o estatuto da filosofia educacional em relação ao passado que sempre distinguiu filosofia de senso comum.

Tais questões surgem quando por volta dos anos 70 acontece 0 grande processo de massificação do ensino nas escolas públicas secundaristas. A escola antes voltada para um público mais seleto, elitista, passa a receber alunos de classes sociais menos privilegiadas. Antes desta época as escolas recebiam um pequeno número de alunos, diga-se de passagem, filhos de famílias de um bom poder aquisitivo que iriam ingressar na Universidade, fato que garantia o ensino de Filosofia voltado para a erudição destas classes, para a introdução num saber esotérico e amplo sobre a realidade. Já que a filosofia tinha o papel de simplificação histórica e teórica do saber filosófico.

Porém, durante o tempo em que a filosofia sofreu represálias a escola mudou seu alvo, diversificou seu público. Tais mudanças se tornaram por um lado, alvo de críticas quanto ao ensino da filosofia no nível médio, depois de sua retomada como disciplina obrigatória. Pois teria que se adequar a uma nova realidade em que o público carecia de uma erudição e tinha deficiências do ponto de vista cultural - uma contradição ao ensino que antes se voltava para proporcionar o esclarecimento de jovens que vinham de camadas sociais médias e superiores com competência linguística e lógico conceitual exigidos para a reflexão filosófica. Por outro lado, tais mudanças foram recebidas como representando um processo de democratização do ensino, da cultura, dos saberes. Um novo desafio aos profissionais da filosofia que se viam agora diante da obrigatoriedade de uma autocrítica, ou seja, repensar o estatuto da história da Filosofia que ao longo de seu desenvolvimento manteve certa distância em relação ao senso comum. Derrida, como contribuição a esta 
ultima posição "propôs que o ensino de filosofia se processasse tomando como ponto de partida o principio ético "direito à filosofia pra todos". 8

Tais mudanças, parecem de fato contradizer toda uma tradição ocidental que se concebeu na efetivação de uma distância em relação à doxa, à opinião. $\mathrm{E}$, ao mesmo tempo traz uma reflexão política quando coloca a questão de uma democracia do saber escolar. Mas a questão é: Como garantir as exigências de uma política educacional, hoje, no que se refere ao ensino da filosofia e à significação diante uma conjuntura educacional que favorece o ensino técnico frente ao valor do conhecimento para uma formação humana papel não único da filosofia, mas de todos os saberes?

Silvio Galo ao tratar desta questão no livro "Filosofia no ensino médio: Tema, problemas e propostas" nos convida a refletir sobre alguns problemas teóricos e práticas no que tange ao ensino filosófico. Um alerta para a insídia que são as competências e habilidades exigidas pelos Parâmetros Curriculares Nacionais, que acabam inviabilizando o real papel da Filosofia. A justificativa do ensino de filosofia no ensino médio é intrigante, ora, sua função reflete-se no papel de desenvolver no aluno a criticidade, permitir a interdisciplinaridade no ensino médio e ainda como sendo necessária ao exercício da cidadania. Para Galo (2007, p.19) essas exigências são perigosas porque esse papel de criticidade e interlocução não deve ser exclusivo da Filosofia, mas de todos os saberes. Quanto ao exercício da cidadania o que é problemático é o fim que é imputado à Filosofia, reduzindo-a à sistematização, a um processo instrumentalizador. ${ }^{9}$ Esta questão é de fundamental importância para discutirmos qual é o papel da Filosofia hoje. Eis que, para nos auxiliar nessa reflexão vamos usar a criticidade das teorias de Benjamin e Deleuze. O pensamento dos dois filósofos se relaciona numa perspectiva metodológica, garantindo à filosofia seu valor de mosaico e de fabricação de conceitos.

\footnotetext{
${ }^{8}$ RODRIGO, 2009, p. 10.

9 “...sabemos que desde suas origens a filosofia resiste a ser tutelada, a ser instrumentalizada. Pelo menos desde Aristóteles a filosofia se caracteriza como um fim em si mesma. Instrumentalizá-la numa política educacional pode significar, pois, sua própria morte. E aí estaríamos no paradoxo dos paradoxos: inserir a filosofia no currículo da educação média, matando a filosofia enquanto movimento, processo, experiência de pensamento não-tutelado" GALO, 2007, p. 20.
} 


\section{Benjamin, Educação e Filosofia}

Em "Origem do Drama Barroco Alemã" Walter Benjamin aponta uma saída do problema de esquematização e sistematização da filosofia. Usando como método o tratado da filosofia e não o da ciência sistemática ele se esquiva das armadilhas de falsas totalizações que privilegia certas posições em detrimento de outras, criando uma polarização de realidade frente a outras realidades. Para Benjamin a filosofia procede pela representação, "comparável ao mosaico justapõe fragmentos de imagem"10. Em seu método de escrita 0 que prevalece é o fragmentário sobre o sistemático, um composto de citações que retoma os pensamentos sem amortiza-las em formas fechadas, hegemônicas.

Na medida em que a filosofia é determinada por esse conceito de sistema, ela corre o perigo de acomodar-se num sincretismo que tenta capturar a verdade numa rede estendida entre vários tipos de conhecimento, como se a verdade voasse de fora para dentro [...] $A$ quintessência do seu método é a representação. Método é caminho indireto, é desvio. A representação como desvio é portanto a característica metodológica do tratado (BENJAMIN, 1984, p. 50).

Por mais que seus escritos não estejam diretamente relacionados com uma teoria da educação, não deixamos de perceber, entrementes, a preocupação política de Benjamin em denunciar, de certa forma, os rumos pérfidos que tomam a educação sob a égide de um estado (alemão) burguês. No texto "O ensino de moral" de 1913, o autor demonstra uma preocupação com a formação das crianças e jovens de modo que a educação não seja pautada numa visão centralista e profissionalizante. Denuncia a educação moral afirmando que esta deve se furtar as esquematizações ou normatizações porque deve ser considerada como assunto inteiramente pessoal e não ter como exigência uma pedagogia absoluta. A preocupação notável de Benjamin com a educação das crianças e dos jovens enaltece um ideal prático político revolucionário frente a um sistema educacional que privilegia o ensino

\footnotetext{
${ }^{10}$ BENJAMIN. Origem do Drama Barroco Alemão. IN: ROUANET,S. P. Apresentação. Tradução, apresentação e notas: Sergio Paulo Rouanet. São Paulo: Brasiliense, 1984.
} 
profissionalizante e interesses utilitaristas. Esta prática seja no ensino básico ou mesmo nas Universidades inviabilizam o potencial criativo e crítico do pensamento. $^{11}$

Não é nada bom quando institutos onde se podem conseguir títulos, qualificações, possibilidades de vida e profissão, se autodenominam redutos da ciência. A objeção de como o Estado atual recrutaria então os seus médicos, juristas e docentes não prova aqui nada em contrário. Mostra apenas a grandeza revolucionária da tarefa: fundar uma comunidade de pesquisadores públicos e de diplomados. Mostra apenas em que extensão as ciências atuais, no desenvolvimento de seu aparato profissionalizante (através do saber e de técnicas) foram desviadas de sua origem comum fundada na ideia do saber, origem essa que se transformou para elas em mistério, quando não em ficção (BENJAMIN, 1915, p. 33).

Ora, no ensino médio, a educação moral é parte constituinte do currículo da disciplina de filosofia, o que nos remete à questão de normatização acrescida a ela como exigência educacional atual. Diante desta situação, surge um questionamento, o de como garantir uma educação pessoal se é sabido que a prática educacional está hodiernamente direcionada para um determinado setor da vida, qual seja, o da técnica ?

O homem dentro do contexto técnico científico perde sua experiência e sua historicidade. A perda da experiência é um dos principais fatores que impedem aos sujeitos o reconhecimento de uma inserção numa realidade social, cultural, estética etc. porque as pessoas perderam suas referências da vida na passagem da vida tradicional para a vida social moderna ${ }^{12}$ em que o

\footnotetext{
${ }^{11}$ a valorização da vida infantil se vincula claramente a uma nova leitura da história, que visa a retomar a tradição e a memória do que foi sufocado, reprimido no processo de constituição da modernidade. Tentar entender a experiência infantil significa questionar com argúcia as formas de educação modernas para tentar uma reformulação teórica condizente com uma nova prática política revolucionária (SCHLESENER, 2010, 129)
}

${ }^{12}$ Pois qual o valor de todo nosso patrimônio cultural, se a experiência não mais o vincula a nós? A horrível mixórdia de estilos e concepções do mundo do século passado mostrou-nos com tanta clareza aonde esses valores culturais podem nos conduzir, quando a experiência nos é subtraída, hipócrita ou sorrateiramente, que é hoje em dia uma prova de honradez 
modelo de comunidade se desintegra para dar vazão ao modelo de um sujeito enclaustrado em si mesmo, de uma vivência particular. Depois da primeira guerra mundial, segundo Benjamin, restaram os traumas e o silêncio. As experiências que sucedem à guerra são pobres em questões comunicáveis, se antes se tinha a tradição de relatar as experiências da vida e transmiti-las oralmente para uma geração, depois de tal ocorrência,

Os livros de guerra que inundaram o mercado literário nos dez anos seguintes não continham experiências transmissíveis de boca em boca. Não, o fenômeno não é estranho. Porque nunca houve experiências mais radicalmente desmoralizadas que a experiência do corpo pela fome, a experiência moral pelos governantes [...] Uma nova forma de miséria surgiu com esse monstruoso desenvolvimento da técnica, sobrepondo-se ao homem. ${ }^{13}$

A formação educacional moderna se configura nesse quadro da técnica como um instrumento para reprodução do poder. A consequência é uma concepção fracassada da vida, uma polarização da média, uma compreensão reinante como se fosse a única realidade possível. A esta polarização, Benjamin chama de média, extraído do elemento conceito, e concebido coo um universal. Para Benjamin trata-se de um pseudo-universal que não consegue dizer a totalidade, e, portanto, nenhuma unidade do particular, que se perde em meio a esta polarização. A linguagem por sua vez, irá se instrumentalizar para representar, portanto, apenas aquilo que a ideologia diz. Ora, mas, se foi dito que o caminho genuíno da investigação filosófica, para Benjamin, se reflete na representação, por uma espécie de desvio (Umweg), então, cabe à filosofia o papel de retomar a dimensão nomeadora da palavra, livrá-la da insídia da técnica que instrumentaliza o ser humano através do seu meio de se fazer comunicável, ou seja, através da linguagem. Essa questão está expressa na metodologia que Benjamin usa para tratar da ideia como algo universal. A ideia é uma configuração dos extremos, uma representação universal. Isso garante o potencial crítico dos seres, pois a ideia não está no mundo empírico, ela é

confessar nossa pobreza. Sim, é preferível confessar que essa pobreza de experiência não é mais privada, mas de toda a humanidade (Benjamin,1974,p.115)

${ }^{13}$ BENJAMIN, Experiência e Pobreza in:_Magia e Técnica, Arte e Política, Tradução de Sérgio Paulo Rouanet, São Paulo: Brasiliense, 1985, p 115. 
representada através do conceito, mas seu lugar comum é a dimensão nomeadora da linguagem em contraponto ao seu caráter significativo e comunicativo.

As ideias se originam na história, são em si mesmas atemporais, apenas quando tomadas pelos conceitos, são polarizadas na média. Benjamin defende que as ideias devem representar os extremos e não se fechar em sistemas. Sendo assim, cabe a filosofia restaurar a dimensão nomeadora da linguagem ${ }^{14}$ onde as ideias se encontram. Uma vez feito isto, encontraremos a origem, a estrutura da linguagem, que podemos entender como um salto em direção ao novo, que supõe um salto no Ser, para além de qualquer processo instrumentalizador ou perda de experiência comunicável. É esse aspecto que interessa a educação. A preocupação de Benjamin é preservar a diferença, a particularidade a partir do respeito, da experiência que se instala no inconsciente permitindo laços sociais, comunitários. A simples vivência, ao contrário, se impõe pela ciência através do conceito que gera choque (Chockerlebnis) nas pessoas, uma vez que afeta o aparelho perceptivo dos sujeitos, agora transformados em autômatos e suscetíveis de programação. Eis, que com isso a experiência entra em declínio. Com o avanço desenfreado da técnica e o ritmo acelerado imposto por ela, o ser humano não tem mais tempo para digerir as mudanças e perde sua semelhança com o todo, perde sua capacidade de se reconhecer no mundo.

O saldo negativo da perda das semelhanças que impede 0 reconhecimento dos laços sociais do homem no mundo ocasionada pela ciência, é a causa de tantas atrocidades cometidas pelo homem nos últimos séculos. Portanto, urgente é que o homem recupere os laços sociais ou os reconstruam através daquilo que ainda subsiste em meio o amontoado de ruínas históricas. Desse modo, devemos entender que apesar de tudo o que a técnica causa de negativo, ela é o resultado de uma interface do conhecimento e devemos analisar o lado positivo da técnica. Nesta compreensão consiste o

${ }^{14}$ A essência linguística das coisas é a sua linguagem; aplicada ao ser humano, essa afirmação significa que a essência linguística do ser humano é a sua língua. [...]a essência linguística do homem está no fato de ele nomear as coisas ( BENJAMIN. Escritos Sobre Mito e Linguagem in:_Sobre a linguagem em geral e sobre a linguagem do homem, Tradução de Jeanne Marie Gagnebin, São Paulo: Editora 34,2011) 
desvio, a representação não apenas de um lado da história, mas no recorte daquilo que pode recontar a realidade. Como na construção de um mosaico Benjamin reconstrói a história e assim reivindica o método da filosofia, através de citações e montagens da História da filosofia, retirando das ruínas aquilo que é necessário para a compreensão do Ser.

Sujeito às vicissitudes da história, a criatura, termo que substitui 'sujeito' deve através do ensino filosófico, na forma de um ensino da moral possibilitar "constituir a transição para um novo ensino de História, no qual, então, também o presente encontre a sua inserção histórico-cultural" (BENJAMIN, 1913, p. 19).

Kothe ao tratar da questão do método em Benjamin diz que sua metodologia se dá por um descaminho, em que a construção de textos é feito por citações que nunca são definitivas ou plenamente aceitas, mas que "entram num jogo de diferenças mútuas capaz de indicar e sugerir a verdade, que não está em nenhuma delas como algo parado e definitivo". Essa postura é uma renuncia à Filosofia enquanto sistema ${ }^{15}$.

Neste sentido, a Filosofia tal como figurada por Benjamin passa a falar por inventividade e, por mais que o material trabalhado seja fornecido pela tradição filosófica ela se presentifica, historicamente, no modelo de um mosaico em que as partes diversificadas darão sentido a uma totalidade no Ser.

\section{Educação e ensino de Filosofia em Deleuze}

\footnotetext{
${ }^{15}$ Não é por acaso que surge explícita a metáfora da "constelação". [...] Cada parte devia iluminar as outras e, assim, ser também iluminada por elas, num processo de lusco-fusco que estabelece uma dinâmica de conexões sempre renovadas entre todas as partes, dando-se uma sugestão de totalidade não rígida nem ditatorialmente exclusiva. Cada uma se caracteriza pelo jogo de diferenças para com as demais e pela retomada aqui e acolá de si mesma. E não é nenhuma imposição a posteriori ver nisso uma correspondência à natureza da linguagem, pois isso é expressamente formulado por Benjamin naquela introdução (KOTHE, 1976, p.28).
} 
$\mathrm{Na}$ análise deleuziana, a educação deve ser compreendida como criação crítica da realidade, exigindo uma articulação construtiva do presente para possibilitar o futuro. Na obra "O que é a Filosofia?" de Deleuze e Guattari, o entendimento e a leitura são avaliados conforme uma virtualidade, uma questão de atualidade do pensamento processual: como uma questão de produção, devir marcado por uma lógica da criação, da diferença e do acontecimento. Para Deleuze a Filosofia deve ser compreendida como criação de conceito, crítica da realidade, exigindo uma articulação construtiva com a história da Filosofia. O papel do conceito pode ser entendido quando se pensa no caráter criativo do gênero humano. Desse modo, a arte, a ciência e a filosofia são as três potências do pensamento, na medida em que permitem o exercício da criatividade. Cada uma à sua maneira permite um mergulho no caos e um lampejo de pensamento novo, criativo. Desse mergulho nos caos o artista traz perceptos e afectos; o cientista traz funções; o filósofo traz conceitos. Assim arte, ciência e filosofia se complementam, cada uma delas permitindo uma experiência distinta de pensamento criativo.

O filósofo é o amigo do conceito, ele é conceito em potência. Quer dizer que a filosofia não é uma simples arte de formar, de inventar ou de fabricar conceitos, pois os conceitos não são necessariamente formas, achados ou produtos. A filosofia, mais rigorosamente, é a disciplina que consiste em criar conceitos. [...] Criar conceitos sempre novos é o objeto da filosofia. É porque o conceito deve ser criado que ele remete ao filósofo como aquele que o tem em potência, ou que tem sua potência e sua competência. Não se pode objetar que a criação se diz antes do sensível e das artes, já que a arte faz existir entidades espirituais, e já que os conceitos filosóficos são também sensibilia. Para falar a verdade, as ciências, as artes, as filosofias são igualmente criadoras, mesmo se compete apenas à filosofia criar conceitos no sentido estrito. Os conceitos não nos esperam inteiramente feitos, como corpos celestes. Não há céu para os conceitos. Eles devem ser inventados, fabricados ou antes criados, e não seriam nada sem a assinatura daqueles que os criam. Nietzsche determinou a tarefa da filosofia quando escreveu: "os filósofos não devem mais contentar-se em aceitar os conceitos que thes são dados, para somente limpá-los e fazê-los reluzir, mas é necessário que eles comecem por fabricá-los, criá-los, afirmá-los, persuadindo 
sobre a relação da amizade com a possibilidade de pensar, no mundo moderno". (DELEUZE, GATARRI, 1992, p. 12).

Embora considerada como uma das potências do pensamento na visão deleuziana, a filosofia, marcadamente perde espaço para os demais saberes, dentro desse formato educacional que privilegia o saber técnico. Uma vez que a ciência ganha supremacia sobre a arte e a filosofia, o que leva estes saberes a serem tomados como coadjuvantes do conhecimento. Desse modo, a Filosofia passa a ser uma reprodução conteudista, fadada à instrumentalização o que a impede de levar os alunos a entrarem no ato e no do processo do filosofar, impossibilitando a criação de novos conceitos. Essa ação reprodutiva da Filosofia no ensino médio inibe tanto o papel reflexivo como as várias formas de agir desse ensino. A proposta, portanto, é buscar um equilíbrio entre as potências da arte, da ciência e da filosofia possibilitando ao aluno da educação média um pensamento criativo, por meio da transversalidade, que garante que a Filosofia continue viva e ativa marcando um novo processo de educar. Neste, o professor deve romper com o ensino que diz aos outros o que deve ser feito, onde a linguagem é considerada como uma palavra de ordem.

Para Deleuze, esse modo de ensinar marca o ensino da modernidade, em que sua crítica do presente consiste em anunciar as possibilidade e mostrar um mundo novo, através de uma significação da realidade. Eis que, romper com essa filosofia significa não mais anunciar a possibilidade do novo, mas sim vivenciar as situações e dentro dessas situações vividas produzir possibilidades do novo. Para esta nova perspectiva surge o professor da diferença, professor este que procura viver a miséria do mundo em suas várias manifestações, quer seja ela econômica, cultural, social ou ética. Vivenciar a mesma miséria que os alunos vivem vai permitir que de dentro desse nível de miséria seja possível construir as possibilidades de um mundo novo, coletivamente. Essa é a ferramenta do professor, uma construção coletiva que permite a liberdade e uma superação para cada indivíduo. Essa forma de educação por meio de uma ferramenta do professor se dá em diversos âmbitos, ou seja, na sala de aula, no local de trabalho do professor, nas relações de sua classe produzindo cultura, política e educação através da literatura menor. Esta se define por três características: A desterritorização da 
língua, a ramificação política e o valor coletivo. O primeiro aspecto da literatura menor reconhece a língua como ligada a uma cultura, como sendo materializada e por isso ela se torna imanente à realidade. A ramificação política diz que a língua é um ato político e por isso exige o estabelecimento de elos, uma multidisciplinaridade que vai garantir de fato esse ato político. E, por último, no valor coletivo, chegamos ao objetivo maior, o de tomar a educação como um agenciamento do todo na construção da realidade de cada indivíduo. O todo permite a construção da realidade sem fazer distinção. Como na educação dialética, a realidade múltipla se torna fundamental para uma consciência heterogênea. A educação passa a falar por milhares como ação coletiva.

Investigar o papel da educação, a partir do pensamento deleuziano é perceber uma ação revolucionária onde teoria e prática se confrontam permitindo o devir na educação. Uma teoria é como uma caixa de ferramenta, diz Deleuze. Levar à compreensão dos mecanismos de utilização dessas ferramentas é a função do professor. A literatura menor proposta por Deleuze gesta uma nova perspectiva, onde a prática repensa 0 pensamento, desterritorizando a língua, permitindo um viver e pensar no presente. A atualização consiste não em um pensamento dado, elaborado, mas sim, em criar possibilidades que permitem a construção da realidade por cada indivíduo, na criação de conceitos, através de mediações do professor. Com base nessa concepção de educação, a proposta, portanto, é levar o professor a repensar as suas práticas de ensino, oferecendo uma educação da multiplicidade, enquanto realidade múltipla que garante a subjetividade, o direito de escolha dos indivíduos.

\section{CONCLUSÃO}

As perspectivas abordadas acerca do método da filosofia tanto a partir do pensamento benjaminiano como deleuziano devem ser encarados aqui como uma resposta positiva ao acesso democrático do ensino de filosofia e como um posicionamento capaz de enfrentar a tentativa de esquematizações, sistematizações do ensino filosófico. Posição que atesta o valor de uma 
filosofia criativa, inovadora e autocrítica, filosofia da diferença em que as possibilidades de mudanças são sempre bem vindas. Pois como acredita Benjamin o sujeito é uma criatura sujeita as vicissitudes históricas, portanto é abertura. Os problemas acerca do ensino da filosofia nas escolas secundárias são problemas concretos, mas devemos encará-los buscando estratégias como a construção de um mosaico benjaminiano que frente às ruínas consegue retirar aquilo que é necessário para a compreensão do Ser.

A proposta a partir destes dois filósofos trabalhados é que busquemos fugir do tecnicismo procurando possibilitar o ato do filosofar como processo de libertação das amarras de um sistema opressor, excludente e desumano. As novas perspectivas do conhecimento, por meio da filosofia de Benjamin e Deleuze, permitem o equilíbrio entre as disciplinas que compõe o currículo escolar do ensino médio e o devir na educação por meio da representação da verdade (Wahrheit) que não se apresenta como posse ${ }^{16}$ (ein Haben), nem se esgota em sistemas.

\section{REFERÊNCIAS}

ARISTÓTELES. Os pensadores. In: metafísica. São Paulo, Abril, 1984.

BENJAMIN, W. Reflexões Sobre a Criança, o Brinquedo e a Educação.

Tradução de M. V. Mazzari. São Paulo: Ed. 34, 2002.

. Escritos Sobre Mito e Linguagem.IN:_Sobre a linguagem em geral e sobre a linguagem do homem, Tradução de Jeanne Marie Gagnebin, São Paulo: Editora 34,2011

. Obras escolhidas I: Magia e técnica, arte e política Trad. De S. P.

Rouanet. São Paulo: Brasiliense,

. Obras escolhidas II: Rua de mão única. Tradução de R. R. Torres

Filho \& J. C. M. Barbosa. São Paulo: Brasiliense,

\footnotetext{
${ }^{16}$ BENJAMIN, W. Origem do drama barroco alemão, Tradução de Sérgio Paulo Rouanet, São Paulo: Brasiliense, 1984, p. 50.
} 
. Origem do Drama Barroco Alemão. Tradução, apresentação e notas: Sergio Paulo Rouanet. São Paulo: Brasiliense, 1984.

Obras escolhidas III: Charles Baudelaire um lírico no auge do

capitalismo. Tradução J.M. Barbosa. H. A. Baptista. -1. Ed.- São Paulo:

Brasiliense, 1989.

CHAGAS. RECH. VASCONCELOS. JOVINO (Org.). Indivíduo e Educação na Crise do Capitalismo. IN: SOUSA, Educação e Indivíduo Pragmático na Crise Capitalista Contemporânea. Fortaleza: Edições UFC, 2012.

DELEUZE, Gilles e GATARRI, Félix. Kafka. Por uma literatura menor.Rio de Janeiro: Imago, 1997.

DELEUZE, G: GUATTARI, F. O que é a Filosofia? Rio de Janeiro: Ed. 34, 1992.

GALLO, Silvio. Deleuze e a Educação. Belo Horizonte: Autêntica, 2008.

GOTO, ROBERTO,J.T.SILVEIRA,RENÉ. Filosofia no ensino médio: temas, problemas e propostas.IN: GALOSão Paulo: Edições Loyola,2007.

KOTHE, F. R. Para Ler Benjamin. Rio de Janeiro, F. Alves, 1976.

MARX, Karl. O capital: crítica da economia política: Livro I: O Processo de Produção do Capital. V.1.26. ed. Rio de Janeiro: Civilização Brasileira, 2008b.

RODRIGO, M. L. Filosofia em sala de aula: teoria e prática para o ensino médio. Campinas, SP: Autores Associados, 2009.

SCHLESENER, Anita Helena. Paidéia. IN: Educação e infância em alguns escritos de Walter Benjamin. jan.-abr. 2011, Vol. 21, No. 48, 129-135. 
INSTITUTO UNIBANCO. JOVEM DO FUTURO. Disponível em http://www.portalinstitutounibanco.org.br/index.php?option=com content\&view=article\&id=10\&lt emid=8 acesso em 29/09/2014

Simone Carlos da Silva - Mestranda pela Universidade Estadual do Ceará (UECE), Brasileira, residente em Fortaleza - CE, E-mail: simone_102006@hotmail.com 